\section{Anisometropia, Ametropia and Amblyopia and Their Effect on Near Visual Acuity}

\author{
Faizan Mehmood, Yogesh Gupta, Ali Raza Rizvi S* and Sukul \\ RR
}

Institute of Ophthalmology, Jawaharlal Nehru Medical College, AMU, Aligarh, UP, India

\begin{abstract}
Amblyopia is well known to be associated with anisometropia and ametropia. However, all anisometropes and ametropes are not amblyopes and the actual frequency of amblyopia is unknown. Whether the amount of deprivation of near vision and distant vision in amblyopes is related, is still a query. The current study aims to evaluate and define these associations. 95 patients of 10-35 years were included in the study that had anisometropia or ametropia of greater than 1 diopter. $70 \%$ of anisometropes and $54 \%$ of ametropes were found to be amblyopes with anisometropia being 2.5 times more associated with amblyopia. Hypermetropia was associated with poorer outcome as compared to myopia. The anisometropic hypermetropes were the worst affected cases with an amblyopia prevalence of $81 \%$ and most of them had moderate to severe amblyopia. There was a strong association between the near and distance visual acuities in amblyopes $(p<0.001)$. Even on comparing myopes and hypermetropes separately, same association was found. So, we can sum up the findings of this study by quoting that anisometropia and ametropia in the absence of any other pathology cause amblyopia which is equal for distance as well as near visual acuity.
\end{abstract}

Keywords: Amblyopia; Ametropia; Anisometropia

\section{Introduction}

Amblyopia is defined as a decrease of visual acuity for which no cause can be detected by the physical examination of the eye. It is usually due to vision deprivation or abnormal binocular interaction. It is reversible if timely corrected [1].

Amblyopia is well known to be associated with anisometropia and ametropia. A considerable amount of literature supports the fact that refractive error alone, be it anisometropia or ametropia, in the absence of strabismus is a risk factor for development of amblyopia [1-5].

*Corresponding author: Ali Raza Rizvi S, Institute of Ophthalmology, Jawaharlal Nehru Medical College, AMU, Aligarh, UP 202002, India, Tel: +91 9837015693 ; E-mail: draliraza12@hotmail.com

Citation: Ali Raza Rizvi S, Mehmood F, Gupta Y, Sukul RR (2015) Anisometropia, Ametropia and Amblyopia and Their Effect on Near Visual Acuity. J Ophthalmic Clin Res 2: 007.

Received: January 22, 2015; Accepted: February 20, 2015; Published: March 06, 2015
Anisometropic amblyopia develops when unequal refractive error in the two eyes causes the image on the one retina to be chronically defocused. This condition is thought to result partly from the direct effect of image blur in the development of visual acuity and partly from intraocular competition or inhibition [1-2]. As little as $1 \mathrm{D}$ of anisometropia has been reported to be associated with hypermetropic anisometropic amblyopia but majority believes that an error of $2.5 \mathrm{D}$ is consistently associated with amblyopia [6-8].

Amblyopia due to bilateral high refractive error (ametropic amblyopia) result from large, approximately equal, uncorrected refractive error in both eyes of a young child [3,4]. An error of $+5 \mathrm{D}$ is needed in both eyes for hypermetropic ametropic amblyopia and $-8 \mathrm{D}$ for myopic ametropic amblyopia [3].

However, all anisometropes and ametropes are not amblyopes. The relationship between refractive error and amblyopia is still not clear. Whether the amount of refractive error is related to the density of amblyopia still remains debatable. Whether the amount of near vision deprivation and distant vision deprivation in amblyopes is related still is a query. The current study aims to evaluate and define these associations.

\section{Material and Method}

This was a cross sectional study to find the association of various types of refractive errors with amblyopia and near vision. After taking informed consent, patients in the age group 10-35 years were included in the study. A thorough ophthalmic examination was done to exclude various factors which could influence the final visual acuity.

The inclusion criteria were:

1.All patients cooperative for refraction (preferably more than 10 years).

2. All patients with refractive error in one eye (anisometropia) or both eyes (ametropia) of more than 1 diopter.

The exclusion criteria were:

- Age less than 10 years or uncooperative for refraction.

- Refractive error less than 1 diopter.

- Presbyopic Correction.

- Manifest squint.

- Anterior segment pathology.

- Posterior segment pathology.

- Previous ocular surgery for any intra-ocular cause.

- Any other condition of the eye which is itself a cause for low vision.

We recorded uncorrected and best corrected visual acuity, both for distance and near. All patients were assessed on Snellen's acuity chart for distance vision and near vision.

The refractive error was processed into spherical equivalent if an astigmatic error was found for the sake of comparability. All patients underwent a retinoscopy under cycloplegia. The assessment of 
Citation: Ali Raza Rizvi S, Mehmood F, Gupta Y, Sukul RR (2015) Anisometropia, Ametropia and Amblyopia and Their Effect on Near Visual Acuity. J Ophthalmic Clin Res 2: 007.

selected patients also included a detailed history, general and detailed ocular examination, including a slit lamp biomicroscopy and fundus examination by indirect and direct ophthalmoscopy.

The collected data was statistically analysed using software SPSS v 20.0 (SPSS Inc., Chicago, Illinois, USA). Data was presented as mean $\pm(\mathrm{SD})$. Chi square test, odds ratio and ANOVA were used as per the type of data. The difference was considered significant at a $p$ value of $<0.05$.

\section{Results}

The following study was conducted on 95 patients who presented to a tertiary eye care centre in northern India after obtaining informed consent. The information was collected on a predesigned proforma. The mean age of patients in our study was $21.8 \pm 7.3$ years. Minimum age included in our study was 10 years and maximum was 35 years.

The frequency of amblyopia was found to be higher in anisometropia group (74\%), as compared to frequency of amblyopia in ametropia, which is $53.66 \%$. On evaluating the association, an odds ratio of 2.5 was found with a confidence interval of $95 \%$ which means that anisometropia is 2.5 times more likely to be associated with amblyopia as compared to ametropia (Table 1).

\begin{tabular}{|l|c|c|c|}
\hline Study Group & $\begin{array}{l}\text { No. of cases with } \\
\text { Amblyopia (\%) }\end{array}$ & $\begin{array}{l}\text { No. of cases without } \\
\text { Amblyopia (\%) }\end{array}$ & Total \\
\hline Anisometropia & $40(74)$ & $14(26)$ & 54 \\
\hline Ametropia & $22(53.66)$ & $19(46.34)$ & 41 \\
\hline Total & $62(65.26)$ & $33(34.74)$ & 95 \\
\hline
\end{tabular}

Table 1: Frequency of amblyopia in cases of ametropia and anisometropia.

We further classified our cases into the following four groups viz., anisometropic myopes, anisometropic hypermetropes, ametropic myopes and ametropic hypermetropes.

It was found that the anisometropic hypermetropes were the worst affected cases with a prevalence of amblyopia of $81.58 \%$, followed by ametropic hypermetropes (64.70\%) and anisometric myopes $(56.25 \%)$. The least affected group was ametropic myopes with an overall prevalence of amblyopia as $45.84 \%$ (Table 2).

\begin{tabular}{|l|c|c|c|c|}
\hline Study Group & $\begin{array}{c}\text { No. of cases } \\
\text { with Amblyopia }\end{array}$ & $\begin{array}{c}\text { No. of cases with- } \\
\text { out Amblyopia }\end{array}$ & Total & $\begin{array}{c}\text { Prevalence } \\
\text { of Amblyopia } \\
\text { (\%) }\end{array}$ \\
\hline $\begin{array}{l}\text { Anisometropic } \\
\text { Myopes }\end{array}$ & 9 & 7 & 16 & 56.25 \\
\hline $\begin{array}{l}\text { Anisometropic } \\
\text { Hypermetropes }\end{array}$ & 31 & 7 & 38 & 81.58 \\
\hline $\begin{array}{l}\text { Ametropic } \\
\text { Myopes }\end{array}$ & 11 & 13 & 24 & 45.84 \\
\hline $\begin{array}{l}\text { Ametropic } \\
\text { Hypermetropes }\end{array}$ & 11 & 6 & 17 & 64.70 \\
\hline Total & 62 & 33 & 95 & \\
\hline
\end{tabular}

Table 2: Distribution of amblyopic cases in various study groups.

However, if we lower our criteria for labelling amblyopia i.e., if we consider that $6 / 9$ as a range of normal vision, we found that amblyopia in anisometropia gets reduced to $63 \%$ from $74 \%$. Amblyopia in ametropia gets reduced to $37 \%$ from $54.66 \%$ (Table 3 ).

\begin{tabular}{|c|c|}
\hline If $\mathbf{6 / 6}$ is considered as normal & If $\mathbf{6 / 9}$ is considered as normal \\
\hline Ametropia $-53.66 \%$ & Ametropes $-37 \%$ \\
\hline Anisometropes $-74 \%$ & Anisometropia $-63 \%$ \\
\hline
\end{tabular}

Table 3: Prevalence of amblyopia in the following scenario
On further classifying the results according to our four major study groups, we found that there is a drastic decrease in the prevalence of ametropic amblyopia, be it myopic or hypermetropic, on lowering the amblyopia labelling criteria by one line whereas anisometropic amblyopia does not get affected to that extent. There was a net decrease in the prevalence of $29.43 \%$ and $16.61 \%$ in ametropic hypermetropes and ametropic myopes respectively. There was a decrease in the prevalence of anisometropic myopes and anisometropic hypermetropes of $12.45 \%$ and $10.44 \%$ respectively (Table 4).

\begin{tabular}{|l|c|c|c|}
\hline & $\begin{array}{l}\text { Amblyopia preva- } \\
\text { lence in our study } \\
\text { according to ATS } \\
\text { (\%) }\end{array}$ & $\begin{array}{l}\text { If 6/9 is taken as } \\
\text { normal prevalence } \\
\text { of Amblyopia (\%) }\end{array}$ & $\begin{array}{l}\text { Net difference } \\
\text { (\%) }\end{array}$ \\
\hline $\begin{array}{l}\text { Anisometropic } \\
\text { Myopes }\end{array}$ & 56.25 & 43.80 & 12.45 \\
\hline $\begin{array}{l}\text { Anisometropic } \\
\text { Hypermetropes }\end{array}$ & 81.58 & 71.14 & 10.44 \\
\hline Ametropic Myopes & 45.84 & 29.23 & 16.61 \\
\hline $\begin{array}{l}\text { Ametropic } \\
\text { Hypermetropes }\end{array}$ & 64.70 & 35.27 & 29.43 \\
\hline
\end{tabular}

Table 4: Prevalence of amblyopia in the following scenario.

\section{ATS: Amblyopia Treatment Study [13]}

Many authors are of the opinion that a minimum of 2.5 diopters of refractive error is required to be able to produce anisometropic amblyopia and even higher refractive error, of the order of 5 diopters, is required to produce ametropic amblyopia [9-12]. But, in our study, we included all patients above $1 \mathrm{D}$ of error and processed our results thereby. Now, if we decide our inclusion criteria according to this fact and exclude all the patients less than 2.5 diopters, there will again be a change in the prevalence of amblyopia. It was found that the prevalence of anisometropic amblyopia increased by $9 \%$ and prevalence of ametropic amblyopia increased by 7\% (Table 5).

\begin{tabular}{|l|c|c|c|}
\hline & $\begin{array}{l}\text { If } \mathbf{1} \mathbf{D} \text { is taken as } \\
\text { inclusion criteria }\end{array}$ & $\begin{array}{l}\text { If } \mathbf{2 . 5} \mathbf{D} \text { is taken as } \\
\text { inclusion criteria }\end{array}$ & Net difference \\
\hline $\begin{array}{l}\text { Anisometropic } \\
\text { Amblyopia }\end{array}$ & $74 \%$ & $83 \%$ & $9 \%$ \\
\hline $\begin{array}{l}\text { Ametropic } \\
\text { Amblyopia }\end{array}$ & $53.66 \%$ & $61 \%$ & $7.34 \%$ \\
\hline
\end{tabular}

Table 5: Prevalence of amblyopia in the following scenario.

\section{(D: Dioptres)}

To observe the effect of amblyopia on distance vision and near vision and to see for a relationship, amblyopia for distance was categorised as mild, moderate and severe according to amblyopia treatment study [13].

A visual acuity of $6 / 6$ on Snellen's was categorised as normal.

Amblyopia for near vision was categorised similarly into mild, moderate and severe according to the corresponding Snellen's equivalent. $\mathrm{N}$ type of near chart was used to record the near vision and subsequently conversion into Snellen's equivalent was made. A visual acuity of N6 was categorised as normal.

We observed that all those who are categorised normal for near vision are also normal for far vision. Moreover, the severe grade of both the groups also coincided to a great extent. Only the moderate and mild categories showed an overlapping pattern (Table 6).

Chi square test was applied and Pearson's coefficient was utilized to interpret the results. It was found in the statistical analysis that the different grades of amblyopia for distance, i.e., normal, mild, 
moderate and severe, are strongly related to the subsequent normal, mild, moderate and severe grades for near vision with a highly significant $\mathrm{p}$ value of less than 0.001 .

We also compared the distant and near visual acuities of myopes and hypermetropes separately (Table 7 and 8). The results were again the same with $\mathrm{p}$ value less than 0.001 on applying Chi square test in both the conditions.

\begin{tabular}{|c|c|c|c|c|c|c|}
\hline \multirow{2}{*}{} & \multicolumn{4}{|c|}{ Grade of Amblyopia for near } & \multirow{2}{*}{ Total } \\
\cline { 3 - 7 } & Normal & Mild & Moderate & Severe & \\
\hline \multirow{2}{*}{$\begin{array}{c}\text { Grade of } \\
\begin{array}{c}\text { Amblyopia for } \\
\text { distance }\end{array}\end{array}$} & Normal & 33 & 0 & 0 & 0 & 33 \\
\cline { 2 - 7 } & Mild & 8 & 7 & 0 & 0 & 15 \\
\cline { 2 - 7 } & Moderate & 5 & 8 & 8 & 6 & 27 \\
\cline { 2 - 7 } & Severe & 0 & 0 & 2 & 18 & 20 \\
\hline \multicolumn{2}{|c|}{ Total } & 46 & 15 & 10 & 24 & 95 \\
\hline
\end{tabular}

Table 6: Amblyopia for near and distance.

\begin{tabular}{|c|c|c|c|c|c|c|}
\hline \multirow{2}{*}{} & \multicolumn{3}{|c|}{ Grade of Amblyopia for near } & \multirow{2}{*}{ Total } \\
\cline { 3 - 7 } & Normal & Mild & Moderate & Severe & \\
\hline \multirow{2}{*}{$\begin{array}{c}\text { Grade of } \\
\text { Amblyopia for } \\
\text { distance }\end{array}$} & Normal & 20 & 0 & 0 & 0 & 20 \\
\cline { 2 - 7 } & Mild & 5 & 1 & 0 & 0 & 6 \\
\cline { 2 - 7 } & Moderate & 3 & 4 & 3 & 0 & 10 \\
\cline { 2 - 7 } & Severe & 0 & 0 & 0 & 4 & 4 \\
\hline \multicolumn{2}{|c|}{ Total } & 28 & 5 & 3 & 4 & 40 \\
\hline
\end{tabular}

Table 7: Near vs. distance vision in myopes.

\begin{tabular}{|c|c|c|c|c|c|c|}
\hline \multirow{2}{*}{} & \multicolumn{4}{|c|}{ Grade of Amblyopia for near } & \multirow{2}{*}{ Total } \\
\cline { 3 - 7 } & Normal & Mild & Moderate & Severe & \\
\hline \multirow{2}{*}{$\begin{array}{c}\text { Grade of } \\
\begin{array}{c}\text { Amblyopia for } \\
\text { distance }\end{array}\end{array}$} & Normal & 13 & 0 & 0 & 0 & 13 \\
\cline { 2 - 7 } & Mild & 3 & 6 & 0 & 0 & 9 \\
\cline { 2 - 7 } & Moderate & 2 & 4 & 5 & 6 & 17 \\
\cline { 2 - 7 } & Severe & 0 & 0 & 2 & 14 & 16 \\
\hline \multicolumn{2}{|c|}{ Total } & 18 & 10 & 7 & 20 & 55 \\
\hline
\end{tabular}

Table 8: Near vs. distance vision in hypermetropes.

So, in our study, there was a strong association found between the near and distance visual acuities in amblyopes, even on comparing myopes and hypermetropes separately.

\section{Discussion}

There has been a great deal of information in literature regarding anisometropia, ametropia and associated amblyopia. However there are some critical questions that have remained unanswered over the time. The relationship between amblyopia and the magnitude of error, relationship of amblyopia and the duration of spectacle use, association between distance and near vision in amblyopes have been sincere topics of debate over the years. Here we have tried to solve some of these queries with the help of our cross sectional study of 95 patients.

The prevalence of amblyopia in anisometropia according to Attebo et al., [1] is $50 \%$ and according to Yekta et al., [2], it is $58.1 \%$. The prevalence of amblyopia in ametropia is $5.97 \%$ according to Karki KJ [14]. In our study a higher prevalence was found, in anisometropes $74 \%$ of the cases were amblyopic and in ametropes $53.66 \%$ cases were amblyopic (Table 1).

However, Ganekal et al., [15] had found a slightly higher occurrence of amblyopia in ametropes than anisometropes i.e., 50\% and $40.9 \%$ respectively.
Worldwide, acuity of $6 / 6$ is accepted as normal and acuities of $6 / 5$ or $6 / 4$ are considered as variants of normal based on individual variations, so why cannot we argue that a visual acuity of 6/9 is also a normal variant based on similar individual variations.

To estimate the effect of this factor, we hypothesized a situation where 6/9 was taken as normal acuity and 6/12 was labelled as amblyopia (Table 3 and 4).

On applying these conditions to our population, we found a dramatic decrease in the prevalence of ametropic amblyopia (be it myopic or hypermetropic), whereas the anisometropic amblyopia showed only a little decrease (Table 3 and 4).

This also leads us to conclude that the depth of amblyopia (referred to as severity) is low in ametropes whereas the anisometropes are severely amblyopic ( $>6 / 24$ best corrected visual acuity).

In our study, a refractive error of \pm 1 diopter was taken into account for inclusion of cases in the study, but according to some literature, anisometropia is considered to be amblyogenic at a difference of 2.5 diopters between the two eyes [9-12]. However, as low as 1 diopter of anisometropia has been found to be associated with amblyopia [6,7].

Thus, if we change our inclusion criterion to 2.5 diopters, instead of 1 diopter, the prevalence of anisometropic and ametropic amblyopia increases by $9 \%$ and $7.34 \%$, respectively (Table 5).

So, it can be easily concluded based upon the above discussion that the defining criteria for anisometropia, ametropia and amblyopia are all arbitrary and a slightest variability of these criteria to the same population can show a dramatic decrease in the prevalence (Table 3 and 4), or a dramatic increase in prevalence (Table 5).

Another factor for this high prevalence may be the inclusion of a higher number of anisometropes and especially hypermetropic anisometropes and these are the patients who are most likely and most severely associated with amblyopia (Table 2).

Use of refractive correction and amblyopia therapy can also affect the final visual acuity of an individual. In our study, no patient had ever received any kind of amblyopia therapy. Out of the 95 patients, 47 had never received any refractive correction. Out of these 47 patients, 37 were in the moderate and severe category of amblyopia. The second largest majority was of the cases that had recently started using refractive correction. There were 35 such cases that were using glasses for less than 5 years. Out of the total, 13 cases were using refractive correction for more than 5 years and 8 of them belonged to the normal and mild category (Table 9).

\begin{tabular}{|c|c|c|c|c|c|c|}
\hline & & \multicolumn{4}{|c|}{ Grade of Amblyopia } & \multirow{2}{*}{ Total } \\
\hline & & Normal & Mild & Moderate & Severe & \\
\hline \multirow{4}{*}{$\begin{array}{l}\text { Duration of use of } \\
\text { refractive correc- } \\
\text { tion in years }\end{array}$} & 0 & 2 & 8 & 23 & 14 & 47 \\
\hline & $\leq 5$ & 12 & 4 & 11 & 8 & 35 \\
\hline & $5-10$ & 3 & 0 & 1 & 0 & 4 \\
\hline & $\geq 10$ & 2 & 3 & 3 & 1 & 9 \\
\hline \multicolumn{2}{|l|}{ Total } & 19 & 15 & 38 & 23 & 95 \\
\hline
\end{tabular}

Table 9: Relationship between duration of use of refractive corrective and the severity of amblyopia. 
Citation: Ali Raza Rizvi S, Mehmood F, Gupta Y, Sukul RR (2015) Anisometropia, Ametropia and Amblyopia and Their Effect on Near Visual Acuity. J Ophthalmic Clin Res 2: 007.

To conclude factors that may be held responsible for this high incidence in our study were:

- Our stringent selection of patients, as any acuity less than 6/6 was labelled as amblyopia. 6/9 on Snellen's chart was taken as mild amblyopia according to Amblyopia Treatment Study [13].

- 1 diopter being used as inclusion criterion as opposed to 2.5 diopters stated by various authors [9-2].

- Relatively small sample size of 95 cases.

- Relatively more cases with hypermetropic anisometropia.

- No history of previous amblyopia therapy and no refractive correction in majority of patients.

- Possible effect of an astigmatic error cannot be overlooked as we have taken into account only the spherical equivalent.

Another major aim of the study was to find association between near and distance vision in amblyopia. Although, not much has been published on this aspect but some scholars like Alex Christoff [16] and GV Catford [17] had found that the depth of amblyopia is similar for distance and near vision.

In our study too, no difference was found in the near and distance visual acuities in amblyopic patients (Table 6).

This was an important question because according to some literature [17], myopes are believed to have a better near vision than distance vision, if they become amblyopic, supposedly due to preserved near vision. But we found that the results for myopes and hypermetropes were similar as far as near and distance vision comparison was considered (Table 7 and 8 ).

\section{References}

1. Attebo K, Mitchell P, Cumming R, Smith W, Jolly N, et al. (1998) Prevalence and causes of amblyopia in an adult population. Ophthalmology 105: 154159.

2. Yekta A, Fotouhi A, Hashemi $\mathrm{H}$, Dehghani $\mathrm{C}$, Ostadimoghaddam $\mathrm{H}$, et al (2010) The prevalence of anisometropia, amblyopia and strabismus in schoolchildren of Shiraz, Iran. Strabismus 18: 104-110
3. Ziylan S, Yabas O, Zorlutuna N, Serin D (2007) Isoametropic amblyopia in highly hyperopic children. Acta Ophthalmol Scand 85: 111-113.

4. Klimek DL, Cruz OA, Scott WE, Davitt BV (2004) Isoametropic amblyopia due to high hyperopia in children. J AAPOS 8: 310-313.

5. Cavazos H, Haase W, Meyer E (1993) Ametropic amblyopia. Strabismus 1: 63-67.

6. Ingram RM, Walker C (1979) Refraction as a means of predicting squint or amblyopia in preschool siblings of children known to have these defects. $\mathrm{Br} \mathrm{J}$ Ophthalmol 63: 238-242.

7. Latvala ML, Paloheimo M, Karma A (1996) Screening of amblyopic children and long-term follow-up. Acta Ophthalmol Scand 74: 488-492.

8. Abrahamsson M, Fabian G, Sjöstrand J (1990) A longitudinal study of a population based sample of astigmatic children. II. The changeability of anisometropia. Acta Ophthalmol (Copenh) 68: 435-440.

9. Abrahamsson M, Sjöstrand J (1996) Natural history of infantile anisometropia. Br J Ophthalmol 80: 860-863.

10. Tanlamai T, Goss DA (1979) Prevalence of monocular amblyopia among anisometropes. Am J Optom Physiol Opt 56: 704-715.

11. Sen DK (1980) Anisometropic amblyopia. J Pediatr Ophthalmol Strabismus 17: $180-184$

12. Rutstein RP, Corliss D (1999) Relationship between anisometropia, amblyopia, and binocularity. Optom Vis Sci 76: 229-233.

13. Pediatric Eye Disease Investigator Group (2002) The clinical profile of moderate amblyopia in children younger than 7 years. Arch Ophthalmol 120: 281287.

14. Karki KJ (2006) Prevalence of amblyopia in ametropias in a clinical set-up. Kathmandu Univ Med J (KUMJ) 4: 470-473.

15. Ganekal S, Jhanji V, Liang Y, Dorairaj S (2013) Prevalence and etiology of amblyopia in Southern India: results from screening of school children aged 5-15 years. Ophthalmic Epidemiol 20: 228-231.

16. Christoff A, Repka MX, Kaminski BM, Holmes JM, Pediatric Eye Disease Investigator Group (2011) Distance versus near visual acuity in amblyopia. J AAPOS 15: 342-344.

17. Catford GV (1956) Amblyopia: a comparison between distance and near vision. Br J Ophthalmol 40: 633-635. 